\title{
CYCLIC FATIGUE RESISTANCE OF PROTAPER GOLD, EDGEFILE, ONESHAPE AND PROTAPER UNIVERSAL
}

\author{
Wafaa Abdel-Baky Khalil*, Khaled Merdad**, Tariq S. Abu-Haimed ${ }^{* * *}$, \\ Mohamed Howait** and Loai Alsofi**
}

\begin{abstract}
Aim: This study aimed to compare the cyclic fatigue of EdgeFile, ProTaper Gold, OneShape, and ProTaper nickel-titanium rotary instruments.

Materials and methods: F2 ProTaper Universal and ProTaper Gold (Dentsply, Tulsa Dental Specialties, Tulsa, OK, USA), C2 EdgeFile (EDGEENDO, Albuquerque, NM, USA), and size 25 OneShape (Micro-Mega, Besançon Cedex, France) (15 instruments each group) were tested for cyclic fatigue in an artificial canal with a $6-\mathrm{mm}$ radius and a $45^{\circ}$ curvature. The number of cycles to fatigue (NCF) was recorded, the lateral surface and fractured face of segments were examined using scanning electron microscopy (SEM), and the cross-sectional area was measured. One-way ANOVAs and Games-Howell tests were utilized for data analysis. A significant difference was set at 0.05 .
\end{abstract}

Results: The EdgeFile had significantly greater resistance to cyclic fatigue, compared with the ProTaper Gold, OneShape, and ProTaper Universal $(\mathrm{p}<0.05)$. No significant difference was found between the OneShape and ProTaper Gold ( $>00.05)$, and the ProTaper Universal exhibited significantly lower resistance to cyclic fatigue compared to the other systems $(p<0.05)$. The OneShape had a significantly smaller cross-sectional area $(\mathrm{p}<0.05)$, while no significance differences were found between the cross-sectional areas of ProTaper Gold, EdgeFile, and ProTaper Universal $(p>0.05)$. No significant differences were found among the groups regarding the length of the fractured segments $(\mathrm{p}>0.05)$.

Conclusion: EdgeFile rotary files have superior resistance to cyclic fatigue, followed in order by the ProTaper Gold, OneShape, and ProTaper Universal rotary files.

* Associate Professor of Endodontics, Department of Endodontics, Faculty of Dentistry, King Abdulaziz University, Jeddah, Saudi Arabia

** Assistant Professor of Endodontics, Department of Endodontics, Faculty of Dentistry, King Abdulaziz University, Jeddah, Saudi Arabia

***Assistant Professor, Department of Conservative Dentistry, Faculty of Dentistry, King Abdulaziz University, Jeddah, Saudi Arabia 


\section{INTRODUCTION}

Rotary instruments fabricated from nickeltitanium (NiTi) have become more widely used. The use of recent NiTi instruments improves the quality of root canal shaping ${ }^{(1)}$. Despite their ability to prepare a curved root canal, they have a tendency to suddenly fracture. A fractured instrument inside a root canal can affect the treatment outcome ${ }^{(2)}$. Instrument fracture during root canal preparation can be attributed to either cyclic or torsional failure. Cyclic failure occurs due to repetitive tension and compression inside curved canals. The efforts of manufacturers are consistently focused on refining the performance of instruments and increasing their life span. Instrument modifications include surface electropolishing ${ }^{(3)}$ and thermal treatment ${ }^{(4)}$ changes in the file design and cross-section ${ }^{(5)}$. Surface electropolishing decreases surface roughness that compromises instrument resistance to cyclic fatigue ${ }^{(6)}$. The OneShape instrument (MicroMega, Besançon Cedex, France) is an example of a regular NiTi file with an electropolished surface and variable cross-section that exhibits good mechanical properties and prepares the canal in less time with respect to the original canal curvature ${ }^{(7,8)}$.

Recently, the thermal treatment of the NiTi alloy optimizes its microstructure and maximizes its flexibility and resistance to cyclic fatigue. The instruments manufactured of M-Wire and controlled memory wires are more resistant to cyclic failure than those made of the traditional NiTi alloy ${ }^{(7,9,10)}$.

ProTaper Gold (PTG, Dentsply, Tulsa Dental Specialties, Tulsa, OK) is a new rotary system that has the same design as the ProTaper Universal, but it includes advanced metallurgy for superior flexibility. The ProTaper Gold exhibits a two-stage transformation behavior and a high $\mathrm{A}_{\mathrm{f}}$ temperature without shape memory, thus resembling controlled memory wires. The ProTaper Gold has a better resistance to cyclic fatigue than the ProTaper Universal $^{(4,11)}$.
The EdgeFilesX3 (EF, EDGEENDO, Albuquerque, NM, USA) is another recently developed electropolished rotary system made of an annealed heat-treated NiTi alloy called Fire-Wire that does not have the shape memory property. This file is compatible with the ProTaper Universal and ProTaper Gold files, and it has a parabolic cross-section and a constant taper of 06 .

No previous study has compared the cyclic fatigue resistance of EdgeFile to other rotary files. Thus, the aim of this study was to compare the resistances to cyclic fatigue of the EdgeFile (EF), ProTaper Gold (PTG), OneShape (OS), and ProTaper Universal (PT).

The null hypothesis tested was that there were no significant differences in the cyclic fatigue resistance of the tested NiTi rotary instruments.

\section{MATERIALS AND METHODS}

Sixty NiTi rotary instruments of four brands (15 files each) with similar ISO tip size \#25 and 25-mm length were tested for cyclic fatigue. The tested instruments were the F2 ProTaper Universal; the ProTaper Gold with $0.08 v$ taper (Dentsply, Tulsa Dental Specialties, Tulsa, OK); the size 25 OneShape with 0.06 taper (Micro-Mega, Besançon Cedex, France); and the C2 EdgeFileX3 with 0.06 taper (EDGEENDO, NM, USA). The Metallurgical Microscope (Model: MX7520, MEIJI TECHNO, Meiji, Japan) at 100x magnification was utilized to inspect the new instruments for defects.

The static mode of cyclic fatigue testing was conducted in a custom-made device similar to that described elsewhere ${ }^{(12)}$. The handpiece was mounted to a stainless block that contained an artificial tapered shape corresponding to tested instruments' dimensions. Its simulated root canal is a size 25 , length of $19 \mathrm{~mm}$, and either a 0.06 or 0.08 taper. All artificial canals have a 6 -mm radius and a $45^{\circ}$ curvature, according to Schneider ${ }^{(13)}$ and the center of the curvature is located $5 \mathrm{~mm}$ from the end (Fig. 1). The handpiece was fixed to the block via a movable device that facilitated the placement of 


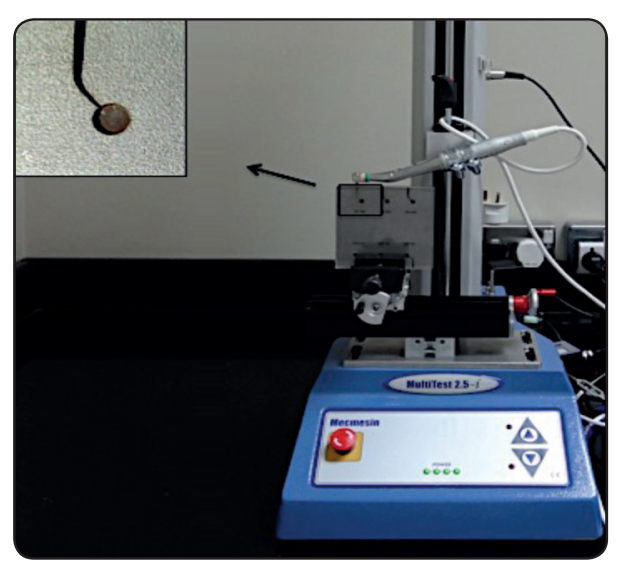

Fig. (1) The custom made system and artificial canal utilized in the present study.

the tested files inside the artificial canal in a precise and reliable manner that guaranteed the placement of all files at the same distance inside. The stainless block is covered by glass to prevent slippage of the instrument during testing. An ACTEON motor (eNDODUAL, MERIGNAC Cedex, France) was used for PT, PTG, OS, and EF following the manufacturers' instructions: PT at $300 \mathrm{rpm}$ and 3 $\mathrm{Ncm}$ torque, PTG at $300 \mathrm{rpm}$ and $5.2 \mathrm{Ncm}$ torque, $\mathrm{EF}$ at $300 \mathrm{rpm}$ and $3 \mathrm{Ncm}$ torque, and $\mathrm{OS}$ at 350 $\mathrm{rpm}$ and $2.5 \mathrm{Ncm}$ torque. To decrease the friction between the files and the canal, artificial oil was applied (Super Oil; Singer Co Ltd., Elizabeth Port, NJ, USA). The instruments were rotated until they fractured. The time to fracture was recorded as $1 / 10$ s using a chronometer. The number of cycles to fracture (NCF) was calculated by multiplying the time (seconds) to failure by the rotations per second. The lengths of the fractured segments were measured using digital microcalipers (Filetta, Schut Geometrical Metrology, Ebnatstrasse, Schaffhausen, Switzerland). The cross-sectional areas of the fractured segments were measured at the same magnification using special software for the Scanning Electron microscope (Quanta 250 FEG, FEI, Eindhoven, Netherlands). Also, their lateral views and the fracture surfaces were photographed at various magnifications $(150 x-1500 x)$. The statistical package used to analyze the data from this study was IBM's SPSS v22 (SPSS, Inc., Chicago,
IL). Simple descriptive statistics were used to study the variables via the means and standard deviations. To compare the mean levels of the four different instruments, this study utilized one-way ANOVAs. These tests were performed after examining the normality of the data distributions using the ShapiroWilk Test and Levene's Test for the homogeneity of variance. A robust test for the equality of means and Welch statistics were used when normality was violated, and the Games-Howell Test was used as an alternative post hoc test. All significant results were based on the conventional cut-off $\mathrm{p}$-value of $<0.05$ for the rejection of the null hypothesis.

\section{RESULTS}

The mean NCF values and cross-sectional area of the segments for each rotary system are represented in Table 1. The EF files exhibited significantly greater resistances to cyclic fatigue followed by the PTG, OS, and PT $(\mathrm{p}<0.05)$. No significant differences were found between the OS and PTG $(\mathrm{p}>0.05)$. The PT exhibited a significantly lower resistance to cyclic fatigue compared to the other systems $(\mathrm{p}<0.05)$. The OneShape had a significantly smaller cross-sectional area $(\mathrm{p}<0.05)$, while no significant difference was found between the cross-sectional area of EdgeFile, ProTaper Gold, and ProTaper Universal ( $>00.05)$. No significance differences were found between the groups regarding the length of the segments $(p>0.05)$. In the lateral view of the fractured instruments, cracks were observed near the fracture sites. The crack propagation followed the machining grooves in the PT file. In the PTG file, the cracks assumed irregular patterns and fracture occurred as a simple fracture or two-plane fractures. The OS file exhibited tortuous and longitudinal cracks parallel to the long axis, while the EF file had irregular horizontal cracks (Figure 2). The secondary electron images showed that the cross-sections of all of the brands exhibited the same fractographic signs of a typical pattern of ductile fracture characterized by the presence of the crack initiation area, fatigue striations, and dimpling areas (Fig. 3). 
TABLE (1) Mean \pm Standard deviation of Number of cycles to fracture (NCF) and cross-sectional area $\left(\mathrm{mm}^{2}\right)$

\begin{tabular}{|l|c|c|}
\hline Group & Mean \pm SD & ${\text { Cross Section Area }\left(\mathbf{m m}{ }^{2}\right)}^{\text {ProTaper Universal }}$ \\
\hline OneShape & $611.60 \pm 56.060^{\mathrm{a}}$ & $0.28 \pm 0.008^{\mathrm{a}}$ \\
\hline EdgeFile & $1031.70 \pm 71.752^{\mathrm{b}}$ & $0.14 \pm 0.006^{\mathrm{b}}$ \\
\hline ProTpaer Gold & $3896.80 \pm 49.910^{\mathrm{c}}$ & $0.24 \pm 0.009^{\mathrm{a}}$ \\
\hline
\end{tabular}

All tested groups were significantly different from each others ( $p<.05)$. SD, standard deviation; different letters indicate significant difference.
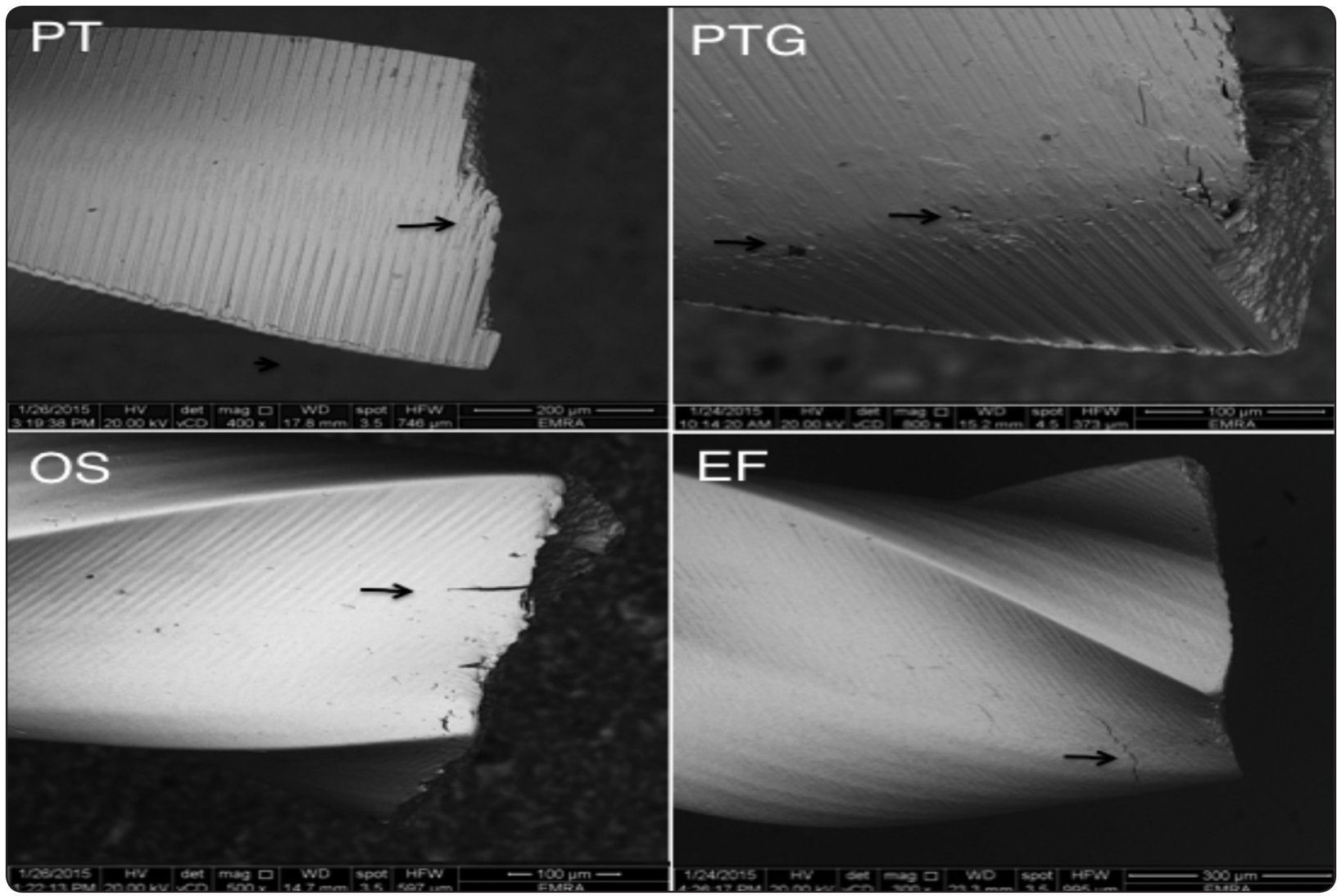

FIG. (2) A scanning electron micrograph showing the lateral view of the instruments after testing with numerous cracks near the fracture sites. With the ProTaper Universal (PT), the cracks run along the machining grooves (arrow). With the ProTaper Gold (PTG), surface pitting and irregular cracks were observed near the fracture site (arrow). With the OneShape (OS), the tortuous and vertical cracks had surface pitting near the fracture site (arrow). With the EdgeFile (EF), zigzagging cracks occurred near the fracture site (arrow). 

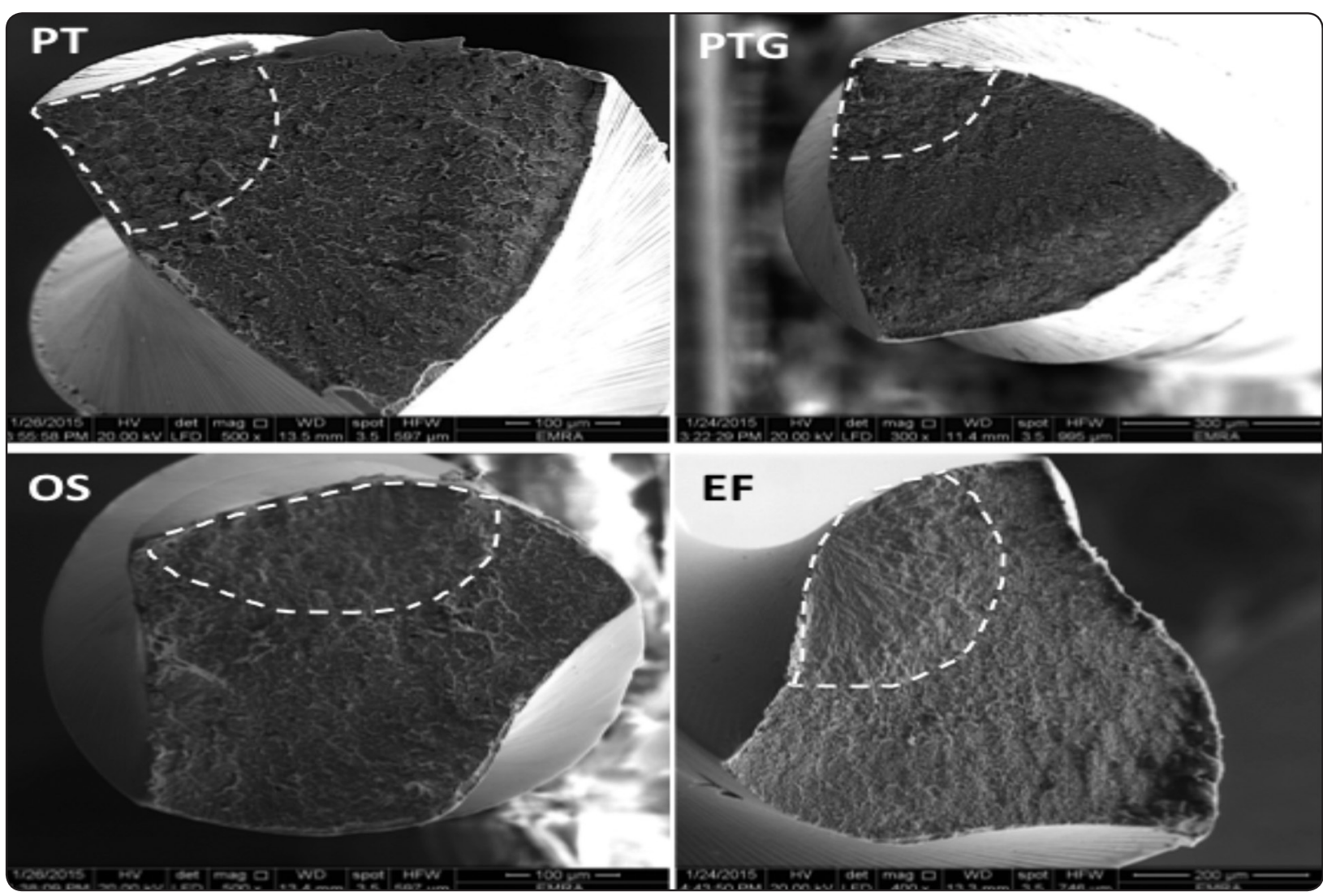

FIG. (3) Secondary electron images showing typical cross-sectional aspects of cyclic fatigue fractures. Outline areas correspond to the fatigue crack nucleation and propagation.

\section{DISCUSSION}

In modern endodontics, many brands have been introduced to the market. Regarding the concerns of clinicians, the file lifetime, efficiency in the preparation of root canals, and treatment outcome are the anticipated benefits of new rotary systems. This study provided a comparison of four recent NiTi rotary instruments in terms of their failures due to cyclic load. The findings of this study provide the endodontists with essential knowledge about the fracture resistance of these instruments. In cyclic fatigue testing, the durability of rotary instruments inside a curved root canal is evaluated. The thermal treatment of different NiTi alloys, surface electropolishing, cross-sectional designs, diameters, and tapers all contribute to a nickel-titanium instrument's tendency for cyclic failure $^{(3,14,15)}$.

Thermal treatment of the NiTi alloy increases the flexibility and impedes crack propagation by preventing the slipping of the crystallography ${ }^{(15-18)}$, while the surface treatment decreases the number of crack initiations and propagation on the smooth electropolished surfaces. According to Lopes et al in $2016^{(6)}$, the increased depths of the surface roughness of the instruments decrease their resistance to fracture. Cross-sectional diameter and geometry affect the instrument resistance to cyclic failure. Ac- 
cording to Kaval et al in $2016^{(11),}$ the cross-section geometry could be considered the most important factor that affects the cyclic fatigue of instruments.

Several previous studies were conducted to compare the different types of NiTi wires ${ }^{(7,19-22)}$. The present study aimed to examine the cyclic fatigue resistance of the $\mathrm{EF}$ file as a recent file manufactured using a thermally treated NiTi alloy. The PTG file was selected as a recent thermal treated instrument compatible with EF file, and neither file has shape memory like controlled memory files. In the meantime, the PT file was selected as the gold standard that represents the regular NiTi alloy and compared to the OS file to study the effects of electropolishing on cyclic fatigue resistance.

The null hypnosis of the present study was rejected as the results indicated the EF file was significantly more resistant than the PTG, OS, and PT files. This finding could be attributable to the flexibility that resulted from the thermal treatment ${ }^{(18)}$, the surface electropolishing ${ }^{(3)}$, and the small parabolic cross-section ${ }^{(23)}$. This finding agrees with those of previous studies that reported the files manufactured from thermally treated alloy and small cross-section exhibit greater resistance to cyclic fatigue ${ }^{(11,16,19)}$. In a recent study, EdgeFile exhibited the highest NCF more than Vortex Blue and ESX files at different temperatures ${ }^{(24)}$.

In the present study, the PTG file was less resistant to cyclic fatigue than the EF file. This could be attributed to the file design, method of thermal treatment, and type of alloy ${ }^{(25)}$. The EF file is made of Fire wire, while PTG is made of a NiTi alloy with advanced metallurgy and a two-phase transformation ${ }^{(4)}$. Moreover, the PTG file has a convex triangle cross-section with 0.08 taper, while the EF file has a small cross-section and 0.06 taper.

The results of the present study indicated that there was no significant difference between the cyclic fatigue resistance of the PTG and OS files. The reason may be the small cross-section of the OS file and its electropolished surface, which give it a higher flexibility ${ }^{(11)}$. Indeed, the PTG file, which is made of advanced metallurgy NiTi wire, would be more resistant to fatigue than the PT file made of regular NiTi with the same file design ${ }^{(4)}$. The enhanced alloy properties of the PTG file are considered the main cause for its superiority ${ }^{(4,11,26,27)}$.

When comparing The OS and PT files as regular NiTi files, the OS file was more resistant to fatigue than the PT file, which is attributable to the surface electropolishing ${ }^{(3)}$. The OS file has the smallest cross-section, while the PT file has a convex triangle. This may add an advantage to the OS file.

In the present study the authors adopted the static mode in testing the cyclic fatigue, which does not represent the clinical situation of dynamic pecking motion performed during mechanical preparation. Another limitation could be the absence of irrigation and its effect on files as modifying factors in the cyclic fatigue of the rotary files. Moreover, an artificial stainless steel canal was used with a different hardness than dentin.

\section{CONCLUSSION}

The EdgeFile nickel-titanium rotary file is more resistant to cyclic fatigue, followed by the ProTaper Gold, OneShape, and ProTaper Universal rotary files when tested in an artificial canal.

\section{ACKNOLEDGEMENTS}

The author's acknowledgement with thanks for the use of the facilities of The Advanced Technology Dental Research Laboratory, Faculty of Dentistry, King Abdulaziz University, for technical support.

The authors declare that they have no conflict of interest. 


\section{REFERENCES}

1. Navos BV, Hoppe CB, Mestieri LB, Bottcher DE, So MV, Grecca FS. Centering and transportation: in vitro evaluation of continuous and reciprocating systems in curved root canals. Journal of Conservative Dentistry 2016; 19 (5): 478-81.

2. Lin LM, Rosenberg PA, Lin J. Do procedural errors cause endodontic treatment failure? Journal of American Dental Association 2005; 136(2): 187-93.

3. Kim BH, Ha JH, Lee WC, Kwak SW, Kim HC. Effect from surface treatment of nickel-titanium rotary files on the fracture resistance. Scanning 2015(1); 37: 82-7.

4. Hieawy A, Haapasalo M, Zhou H, Wang ZJ, Shen Y. Phase transformation behavior and resistance to bending and cyclic fatigue of ProTaper Gold and ProTaper Universal instruments. Journal of Endodontics 2015; 41(7): 431-3.

5. Pedulla E, Lizio A, Scibilia M, Grande MN, Plotino G, Boninelli S, et al. Cyclic fatigue resistance of two nickeltitanium rotary instruments in interrupted rotation. International Endodontic Journal 2017; 50(2): 194-201.

6. Lopes HP, Elias CN, Vieira MV, Vieira VT, de Souza LC, Dos Santos AL. Influence of surface roughness on the fatigue life of nickel-titanium rotary endodontic instruments. Journal of Endodontics 2016;42(6):965-8.

7. Dagna A, Poggio C, Beltrami R, Colombo M, Chiesa M, Bianchi S. Cyclic fatigue resistance of OneShape, Reciproc, and WaveOne: An in vitro comparative study. Journal of Cnservative Dentestry 2014; 17(3): 250-4.

8. Burklein S, Jager PG, Schafer E. Apical transportation and canal straightening with different continuously tapered rotary file systems in severely curved root canals: F6 SkyTaper and OneShape versus Mtwo. International Endodontic Journal 2017; 50(1):983-90.

9. Alapati SB, Brantley WA, Lijima M, Clark WA, Kovarik L, Buie C, et al. Metallurgical characterization of a new nickel-titanium wire for rotary endodontic instruments. Journal of Endodontics 2009; 35(11): 1589-93.

10. Plotino G, Testarelli L, Al-Sudani D, Pongione G, Grande NM, Gambarini G. Fatigue resistance of rotary instruments manufactured using different nickel-titanium alloys: a comparative study. Odontology 2014; 102(1): 31-5.

11. Kaval ME, Capar ID, Ertas H, Sen BH. Comparative evaluation of cyclic fatigue resistance of four different nickeltitanium rotary files with different cross-sectional designs and alloy properties. Clincal Oral Investigations. 2016; 21(5): 1527-30.

12. Pedulla E, Grande NM, Plotino G, Gambarini G, Rapisarda E. Influence of continuous or reciprocating motion on cyclic fatigue resistance of 4 different nickel-titanium rotary instruments. Journal of Endodontics 2013; 39(2): 258-61.

13. Schneider SW. A comparison of canal preparations in straight and curved root canals. Oral Surgery Oral Medicine Oral Pathology. 1971; 32(2): 271-5.

14. Yao JH, Schwartz SA, Beeson TJ. Cyclic fatigue of three types of rotary nickel-titanium files in a dynamic model. Journal of Endodontics. 2006; 32(1): 55-7.

15. Shen Y, Zhou HM, Zheng YF, Peng B, Haapasalo M. Current challenges and concepts of the thermomechanical treatment of nickel-titanium instruments. Journal of Endodontics. 2013; 39(2): 163-72.

16. Braga LC, Faria Silva AC, Buono VT, de Azevedo Bahia MG. Impact of heat treatments on the fatigue resistance of different rotary nickel-titanium instruments. Journal of Endodontics 2014; 40(9): 1494-7.

17. Zhou HM, Shen Y, Zheng W, Li L, Zheng YF, Haapasalo M. Mechanical properties of controlled memory and superelastic nickel-titanium wires used in the manufacture of rotary endodontic instruments. Journal of Endodontics 2012; 38(11):.1535-40.

19. Capar ID, Kaval ME, Ertas H, Sen BH. Comparison of the cyclic fatigue resistance of 5 different rotary pathfinding instruments made of conventional nickel-titanium wire, M-wire, and controlled memory wire. Journal of Endodontics. 2014; 41(4): 535-8.

20. Elnaghy AM, Elsaka SE. Torsion and bending properties of OneShape and WaveOne instruments. Journal of Endodontics 2015; 41(40: 544-7.

21. Higuera O, Plotino G, Tocci G, Carrillo G, Gambarini G, Jaramillo DE. Cyclic fatigue resistance of 3 different nickel-titanium reciprocating instruments in artificial canals. Journal of Endodontics. 2015; 41(6):913-5.

22. Shen Y, Hieawy A, Huang X, Wang ZJ, Maezono H, Haapasalo M. Fatigue resistance of a 3-dimensional conforming nickel-titanium rotary instrument in double curvatures. Journal of Endodontics. 2016; 429(6): 961-4. 
23. Cheung GS, Darvell BW. Low-cycle fatigue of NiTi rotary instruments of various cross-sectional shapes. Int Endod J. 2007; 40(8): 626-32.

24. Dosanjh A, Paurazas S, Askar M. The Effect of Temperature on Cyclic Fatigue of Nickel-titanium Rotary Endodontic Instruments. Journal of Endodontics 2017;43( 5):823-826.

25. Ha JH, Kim SK, Cheung GS, Jeong SH, Bae YC, Kin HC. Effect of alloy type on the life-time of torsion- preloaded nickel titanium endodontic instrument. Scanning 2015;
37(3): 172-8

26. Uygun AD, Kol E, Topcu MK, Seckin F, Ersoy I, Tanriver M. Variations in cyclic fatigue resistance among ProTaper Gold, ProTaper Next and ProTaper Universal instruments at different levels. International Endodontic Journal. 2015;49(5):494- 9.

27. Elnaghy AM, Elsaka SE. Mechanical properties of ProTaper Gold nickel-titanium rotary instruments. International Endodontic Journal. 2016; 49(11): 1073-8. 